\title{
Un palacio para un héroe: la representación del Sagrado Palacio Imperial de Constantinopla en el Tirant lo Blanc
}

\author{
Teresa IZQUIERDo ARANDA \\ Universidad de Valencia \\ teresa.izquierdo@uv.es
}

\section{RESUMEN}

Joannot Martorell recupera el Gran Palacio Imperial de Constantinopla en el capítulo griego de su Tirant lo Blanc, con la intención de proporcionar un recinto primordial para la proyección heroica de su protagonista. Tirant realiza en la ficción un sueño imposible ya en la realidad. Resucita el signo áulico de la capital del Bósforo como auténtica Segunda Roma, rescata un entramado erigido en heredero del antiguo Imperio dentro de la órbita cristiana. En este artículo, analizaremos con detalle los recursos empleados por Martorell para recrear del entorno palatino y valoraremos la aportación del texto literario como fuente para la Historia del Arte.

Palabras clave: Tirant lo Blanc, Constantinopla, Sagrado Palacio Imperial, Literatura, Arquitectura.

\section{A palace for a Hero: The Imperial Holy Palace of Constantinople in Tirant lo Blanc}

\begin{abstract}
Joannot Martorell recovers the Gran Palacio Imperial de Constantinople in the Greek chapter of Tirant lo Blanch, in order to provide a symbolic space to the heroic projection of his main character. Tirant achieves in the fiction an impossible dream even in reality.

Uses the capital of Bosphorus as a symbol for a real New Rome and rescues an enclosure that in the Christian sphere becomes the heir of the ancient Empire. In this article we will analyze with detail the resources employed by Martorell to recreate the palace environment and value the contribution of the literary text as a source for History of Art.
\end{abstract}

Key words: Tirant lo Blanc, Constantinople, Sacred Palace, Literature, Architecture. 
En ningún lugar como en Constantinopla se esforzó Joannot Martorell por resaltar la esencia ambiental y paisajística de las escenas presentadas en el Tirant lo Blanc. Salvar Constantinopla era un tópico novelesco que ya recogía el Guy de Warwick doscientos años antes de la caída definitiva del Imperio. Martorell no eligió Constantinopla por azar; bajo las tensiones del recelo, admirada y envidiada por igual, su pérdida supuso un golpe difícil de asimilar para las conciencias cristianas impotentes ante el hundimiento definitivo de Bizancio. Metáfora de los afanes cristianos, su toma el 29 de mayo de 1453 confirió una insospechada actualidad a su relato ${ }^{1}$. El escritor se informó con detalle sobre la organización del territorio, sus infraestructuras y edificios, las características del paisaje y la orografía para componer una ficción creíble y asimilable, aunque las distorsiones históricas fuesen una llamada incesante a la prudencia ${ }^{2}$. Estimula la imaginación del lector en la descripción del mundo bizantino en el que combina el fasto de castillos y palacios propio de la órbita europea con la tradición artística bizantina ${ }^{3}$. Episodio vital en la novela, el amor en Tirant inaugura una faceta inédita que lo hará vulnerable y, con ello, definitivamente humano ${ }^{4}$.

\section{El viaje a Constantinopla en la literatura medieval}

Sumándose al llanto por la pérdida del Imperio, la novela se incorpora en cierta manera a ese nuevo género literario de las lamentaciones por la ciudad perdida, más exactamente, por el palacio y la corte imperiales 5 . Admira la descripción apurada que aporta sobre el Sagrado Palacio Imperial, más aún al considerar la excepcional prodigalidad de sus descripciones, que se recrean en la singularidad de los prodigios que encuentra a cada paso, en la línea del exotismo ya evocado por novelas como Historia de Jacob Xalabín ${ }^{6}$. En la línea de ese renovado interés por Oriente, también Garci Rodríguez de Montalvo en el quinto libro de la saga del Amadís de Gaula, incorporaba novedades significativas en el sentido del viaje al orientar el destino de

\footnotetext{
1 L. BADIA, "El Tirant en la tardor medieval catalana", Actes de Symposion Tirant lo Blanc, Barcelona, 1993, p. 40.

2 M. DE RIQUER, "La novel-la cavalleresca", M. RIQUER, A. COMAS, A y J. MOLAS (eds.), Història de la Literatura catalana, Esplugues de Llobregat, 1984-1988, pp. 370- 371. En el romance del siglo XIII, sitiada Constantinopla por el Soldado de Babilonia, el conde acude a auxiliar al emperador quien, en agradecimiento, le ofrece a su hija Laurette en matrimonio, premio que por el contrario está vedado al caballero obligado a guardar fidelidad a su dama. Desarrolla una trama similar a la del capítulo griego de la novela de Martorell. Respecto a la elección de Constantinopla por Martorell y el realismo con el que la recrea, Martí de Riquer señala que el autor tendría presente el testimonio de Pedro Vázquez de Saavedra en el momento en que llegaron de Roma mensajeros de Felipe de Borgoña para conformar un contingente de ayuda. Véase M. DE RIQUER, Aproximació al Tirant lo Blanc, Barcelona, 1990, p. 167- 172.

3 F. GADEA e I. CÒNSUL, Tirant lo Blanc. Guia de lectura, Barcelona, 1990, p.34.

4 M. VARGAS LLOSA, Carta de batalla por Tirant lo Blanc, Barcelona, 1991, pp. 87-106. Idea general extraída de su artículo "Las palabras como hechos".

5 R. MONTAÑÉS, "El viaje y los viajes en la literatura bizantina", R. BELTRÁN (ed.), Maravillas, peregrinaciones y utopias: literatura de viajes en el mundo románico, València, 2002, p. 378.

6 Història de Jacob Xalabín, L. BADÍA (ed.), Barcelona, 1982. Es una obra escrita sobre el terreno, probablemente entre 1389 y 1404 y ambientada precisamente en Constantinopla.
} 
su protagonista hacia Constantinopla ${ }^{7}$. En el Tirant lo Blanc este factor de caprichoso determinismo en el itinerario iniciático del héroe es sustituido por la idea de la cruzada utópica, introducida por Ramon Llull en Blanquerna a finales del siglo XIII. El protagonista cumple en la ficción un ideal ya imposible en la realidad, ahora bien, en esta fabulosa ficción creada por Martorell, el peso del factor realista reduce la especulación imaginativa para conducirnos por situaciones identificables, capaces de satisfacer la curiosidad y al afán de conocimiento del lector coetáneo ${ }^{8}$. De este modo, los paisajes, los monumentos, las costumbres, los vestidos, incluso las comidas son descritas con cercana inmediatez, desde la óptica de la belleza y la sensualidad que Tirant encuentra en Constantinopla.

En este sentido, creemos suficientemente significativo el valor que el autor otorga al Sagrado Palacio de Constantinopla en su interés por ennoblecer la arquitectura y el entorno de un núcleo neurálgico en el peso argumental de la obra, primordial para la proyección heroica de su protagonista. Resucita el signo áulico de la capital del Bósforo para rescatar un entramado que en el imaginario colectivo se había erigido en símbolo del esplendor del antiguo Imperio. En su descripción agudiza el gusto por el detalle, se esfuerza por retratar una arquitectura fabulosa, introduciendo en el relato un matiz de fantástico artificio. Su restitución se convierte en el sueño encarnado por un solo héroe, el suyo, a quien prepara a conciencia el escenario más ambicioso, Constantinopla, convertida en topo literario para la culminación de la leyenda ${ }^{9}$. La narración se presenta en principio como una soberbia manipulación histórica que obliga al lector a considerar los límites entre la realidad y la invención, los personajes desfilan en procesión recibiendo homenajes de pabellón en pabellón, en un laberinto de habitaciones, patios, salones, terrazas y capillas en el que es imposible concretar la estancia exacta en la que se hallan, pero que capta a la perfección esa impresión esponjosa y confusa de salones de trazados artificiosos y la complejidad de su programa decorativo. Esparcida a lo largo de más de un centenar de capítulos, la descripción del Palacio Imperial se descubre fascinante. Una lectura minuciosa del laberinto de edificios y patios revela el acierto de la visión proyectada en la novela, fruto sin duda de la atenta lectura realizada por el autor de las fuentes a su alcance al recuperar el Sagrado Palacio como emblema de inestimable valor simbólico.

7 J.E. SALES DASÍ, "Literatura de viajes y libros de caballerías. La crónica de Adramón”, R. BELTRÁN (ed.), op. cit., 2002, p. 386. El viaje del protagonista de las Sergas de Esplandián está orientado por la maga Urganda la Desconocida que lo conduce a parajes que enfatizan el encanto.

8 R. BELTRÁN, "Una mirada actual al viaje desde el Mediterráneo a Oriente en la Edad Media", R. BELTRÁN (ed.), op. cit., 2002, p. 416.

9 J. PUJOL, La memòria literària de Joanot Martorell. Models i escriptura en el Tirant lo Blanc, Barcelona, 2002, p. 63. Dentro de la órbita cristiana, la conversión de Constantinopla en un topos de la literatura coetánea se desarrolla en un período significativo motivada por los frecuentes contactos entre los reinos occidentales y el Imperio de Oriente iniciados en el siglo XII con las primeras expediciones emprendidas por comerciantes y embajadas diplomáticas. 


\section{Relatos y testimonios: las fuentes al alcance de Martorell}

Para conocer la fisonomía del Gran Palacio las mejores fuentes de información disponibles, aún en la actualidad, eran las noticias aportadas por testigos contemporáneos. En esta línea se hallaban contribuciones como el Libro de Ceremonias del propio emperador Constantino VII Porfirogeneta (913-959), destacan también las crónicas de visitantes extranjeros, como los embajadores de la dinastía china T'ang a la corte de Miguel III Paleólogo, o las relaciones de viajeros como Liutprando de Cremona ${ }^{10}$. Testimonios más cercanos fueron los relatos de Benjamín de Tudela, cuyas notas recogían las impresiones de un largo recorrido por Europa y Oriente, que iniciaría entre 1159 y 1167 y completaría a su regreso hacia 1172 o $1173^{11}$. Precisamente una misión diplomática motivó la redacción de la Embajada a Tamorlán de Ruy González de Clavijo, uno de los integrantes del séquito que Enrique III de Castilla envió a la corte de Samarcanda en 1403. El relato es un auténtico diario de viaje en el que el autor da cuenta con absoluta inmediatez los escenarios y sucesos de cada jornada del trayecto, con una decidida vocación de actualidad y precisión ${ }^{12}$.

A estos informadores directos se añadieron aún las noticias de cruzados y peregrinos que, desde la primera llamada de Gregorio VII a los milites Christi en 1074, habían acudido en ayuda del Imperio bizantino ${ }^{13}$. De estas noticias se hicieron eco, también teólogos e intelectuales que, impelidos por el relieve del impacto político causado por la amenaza otomana, trataron de evocar los prodigios de Constantinopla, convertidos en tópicos literarios dentro de la tradición de los Mirabilia Urbis Romae y de los libros de peregrinajes como Le Pèlerinage de Charlemagne ${ }^{14}$. En el momento de la redacción de nuestra novela, la ofensiva islámica y la transcendencia del golpe definitivo de mayo de 1453 potenciaron más si cabe la inquietud por la historia, los edificios y el protocolo bizantinos, bien conocidos y difundidos por crónicas de viajeros como Ramón Muntaner o Pero Tafur que se convirtieron en delegados documentales de primera mano ${ }^{15}$.

10 J. BECKWITH, Arte paleocristiano y bizantino, Madrid, 1997, p. 220.

11 B. DE TUDELA. Libro de viajes de Benjamín de Tudela. J. R. MAGDALENA (ed.), Barcelona, 1982.

12 R. GONZÁlEZ DE CLAVIJO, Embajada a Tamorlan, M. A. PÉREZ PRIEGO (ed.), Embajada a Tamorlán. Andanças e viajes de Pero Tafur. Diarios de Colón, Madrid, 2006.

13 La primera llamada se produjo en respuesta a la derrota sufrida en 1071 por el ejército bizantino en la batalla de Manzikert ante las tropas de los turcos selyúcidas, que a pesar de no recibir una amplia respuesta, sirvió para atraer la atención sobre los conflictos en Oriente.

14 J. MARTORELL, (M. J. de GALBA), Tirant lo Blanch, A. HAUF, A. I. PEIRATS y V. ESCARTÍ (eds.), València, 2005, p. 488. Destaca la coincidencia de obras más próximas al Tirant como La Faula de Torroella que también se hicieron eco de las maravillas bizantinas.

$15 \mathrm{Si}$ bien la crónica de este hidalgo andaluz era fruto de un relato retrospectivo de sus aventuras, en el que se interesaba por las peculiaridades geográficas de cada región, por los sistemas de gobierno y las infraestructuras de las ciudades y los reinos que había visitado. Su atenta observación y sus reflexiones alejaban su testimonio de la imagen estereotipada de Oriente, para referir las peculiaridades de sus fiestas y tradiciones y describir con fría objetividad el estado en que se hallaban las principales iglesias y monumentos de Constantinopla. Véase M. DE RIQUER, Tirant lo Blanc, novela de historia y de ficción, Barcelona, 1992, p. 161. P. TAFUR, Andanças e viajes, M. A. PÉREZ PRIEGO (ed.), op. cit., 2006, pp. 180 -181. 


\section{La recreación martorelliana}

Martorell, de quien no hay documentada ninguna estancia en tierras bizantinas, asistió indirectamente a la caída definitiva de la ciudad ${ }^{16}$. Para encuadrar su fábula desestimó ingeniosamente Blanquernas para recuperar la imagen del Sagrado Palacio como símbolo de la época de esplendor del Imperio Oriental y ennoblecer las gestas de su protagonista. La narración se esfuerza en detallar la magnificencia del palacio mediante referencias a interiores de palacios europeos con tal de recrear un ámbito plausible, asimilable para el lector coetáneo y suplir así la pobreza de los restos certificada por las crónicas y la escasa precisión de sus propios conocimientos. Dosifica la información con meticulosidad, respetando a grandes trazos la disposición estructural del Gran Palacio Imperial y, allá donde su conocimiento sobre los vestigios conservados o donde las fuentes no alcanzaban, compensa el vacío con evocaciones y sugestiones ambientales genéricas para no traicionar la veracidad ni la innegable singularidad de la arquitectura palatina tardo-antigua de Bizancio ${ }^{17}$.

Emplaza la residencia de la familia imperial en el corazón de la ciudad, desde allí el Emperador camina hasta el puerto del Bukoleon para recibir a Tirant desde la terraza de la llamada Casa de Justiniano, cuyo frente se abría a orillas del mar de Mármara ${ }^{18}$. Tras el desembarco, el desfile triunfal bordea la muralla para dirigirse al Augusteon ${ }^{(a)}$, la plaza de la que partía la Mesè, la larga avenida que articulaba el entramado urbano de la ciudad y entrada a palacio a través de un portal flanqueado por una "piña toda de oro, de la altura de un hombre y muy gruesas" fácilmente identificable con la Puerta de Bronce o Chalke $e^{(\mathrm{e})}$, un pórtico cubierto por un continuo de bóvedas de cañón que descansaban al exterior sobre enormes columnas simbólicamente elaboradas. Este portal monumental daba acceso a una explanada a cuya izquierda se erigía la iglesia de Santa Sofía ${ }^{19}$.

Estas breves indicaciones descartan la residencia en el distrito de Blanquernas, que habría sido la localización natural para la familia imperial en la época, donde de hecho habitaba desde que Alejo I Comneno (1081-1118) trasladara la sede palatina al noroeste de la capital junto al Cuerno de Oro. Este domicilio es substituido en la novela por el antiguo Sagrado Palacio Imperial, conocido también como Gran Palacio, que constituía un soberbio conjunto de edificaciones fundado por el emperador Constantino en el año

\footnotetext{
16 Martorell viajó a Gran Bretaña en 1438 para solicitar a Enrique IV de Lancaster que mediase como juez en su combate contra su primo Joan de Montpalau, a quien había retado por medio de una lletra de batalla a ultrança por haber violado a su hermana Damiata. En 1443 visitó Portugal y en 1454 se embarcó a las órdenes de Alfonso el Magnánimo rumbo a Nápoles, donde permaneció doce años. De este modo, pese a no haber visitado jamás Constantinopla, por medio de estas estancias, obtuvo un abundante material y una gran experiencia en los viajes para su novela. Véase J. VILLALMANZO CAMENO, Joanot Martorell: biografía ilustrada y diplomatario, Valencia, 1995, p. 72.

17 R. KRAUTHEIMER, Arquitectura paleocristiana y bizantina, Madrid, 2000, pp. 82-83.

18 La conocida como Casa de Justiniano fue construida a finales del siglo IV, ampliada y remodelada sucesivamente hasta el siglo VIII. El Libro de Ceremonias la describe como una gran explanada cubierta a la que se accedía por un portal de mármol que se correspondía en la parte superior con una larga balaustrada.

19 R. KRAUTHEIMER, op. cit., 2000, pp. 270, 281-282, 404- 405. La iglesia de Santa Sofía era a un tiempo la catedral de Constantinopla y la iglesia del Gran Palacio, cuyo ceremonial estaba organizado para la participación de emperador, como bien refleja la asiduidad con la que los personajes asisten a los oficios en diversos episodios de la novela.
} 
330, sucesivamente ampliadas por Justiniano I (518- 527), Teófilo (829 -842) y Basilio I (867- 886). A raíz del saqueo de Constantinopla en abril de 1204 durante la Cuarta Cruzada el recinto fue progresivamente abandonado. De hecho cuando el ejército de Miguel VIII Paleólogo (1259- 1282) recuperó la ciudad en 1261 el palacio se encontraba ya en un estado ruinoso, lo que propició el traspaso de las funciones de gobierno a Blanquernas ${ }^{20}$. La ausencia de la autoridad imperial y las carencias económicas precipitaron su deterioro durante la siguiente centuria, de modo que cuando las tropas de Mehmet II irrumpieron en la capital en 1453, de la magnificencia del Sagrado Palacio quedaban a penas las ruinas nominales.

Martorell recuperó conscientemente el recinto palacial como testimonio insigne de la Nea Roma Constantinopolis que desde su fundación en el año 324 se había erigido como centro arquitectónico de primer orden y constituía para la civilización occidental un símbolo de la riqueza cultural del Imperio Bizantino ${ }^{21}$. Acomodó así a la familia imperial en un palacio que había llegado a abarcar un área aproximada a las cuarenta hectáreas, que comprendía la zona donde se erige hoy la gran mezquita conocida como Top-capi del sultán Ahmed. Apostado en las inmediaciones del puerto, estaba delimitado al este por el mar de Mármara, al oeste por el Hipódromo y al norte por la plaza del Augusteon y la iglesia de Santa Sofía, espacios que descuellan bien situados en el transcurrir de la acción. En conjunto comprendía una vasta superficie de alojamientos imperiales, salones de recepción, iglesias, almacenes, talleres, patios y magníficos jardines, coherentemente captada por su pluma.

En este sentido, tras recopilar los datos esparcidos en el capítulo griego reconocemos en Tirant lo Blanc una rica fuente para aproximarnos, si no a la construcción original, sí al menos a esa hipotética restitución que el imaginario europeo había conjeturado acerca del recinto. Gracias a la reconstrucción del plano palatino elaborada por C. Vogt en 1935, con base en la información aportada por el emperador Constantino VII, es posible valorar en efecto el conocimiento que Martorell tenía de su estructura y su distribución. El autor se documentó cuidadosamente al redactar su novela y al evocar una esmerada selección de espacios en los que planteó siempre un amplio margen de ambigüedad para situar al lector en un contexto creíble, conveniente a los propósitos de la narración. En sus descripciones predomina así un cierto distanciamiento, la dosis de imprecisión conveniente para no delatar el deterioro en que se hallaban en realidad las trazas del palacio, ni el débil soporte sobre el cual diseñó el paisaje descrito.

\section{Salas de audiencia y de recepción}

Desde el patio el cortejo accede a una suntuosa sala identificable con la Magnaura ${ }^{(\mathrm{f})}$, el principal salón del trono en época macedónica, aunque su construcción datara probablemente de época constantiniana. El estrado imperial estaba guarnecido por

20 J. BECKWITH, op. cit., 1997, p. 187.

21 R. KRAUTHEIMER, op. cit., 2000, pp. 81-83, 89-91, 259, 282 y 404-412. Las noticias aportadas por el historiador sobre el Sagrado Palacio han constituido la base de referencia para la elaboración del presente estudio, a ellas remitiremos a medida que avance el análisis. 
"muchos osos y leones atados con cadenas de plata" con los que el autor refiere los leones autómatas de bronce o madera dorada capaces de batir el suelo con sus colas, rugir y mover la lengua descritos Liutprando de Cremona en su primera visita a la corte bizantina ${ }^{22}$. Las estancias principales se localizaban en la planta noble, a la que se accedía mediante la escalera principal ubicada en la entrada, ante la que Martorell sitúa la cámara en la que el emperador se retira para atender los asuntos de gobierno, el Kainourgion de Basilio I, edificado entre los años 867 y $886^{23}$. Tras el recibimiento, la corte reclama a Diafebus noticias de los festejos de Inglaterra, Sicilia y Rodas, para escuchar su relato se congregan en una sala decorada "por arte de muy sutil artificio", con las paredes recubiertas de mosaicos, "que lanzaban muy gran resplandor". Las gestas se recitan en verso como si se tratase de un roman declamado a la corte al estilo de los grandes ciclos caballerescos. Sobre los muros e invadiendo la bóveda, figuran hazañas de la Antigüedad y de los triunfos del emperador en la línea de los mosaicos añadidos por Manuel I Comneno (1143-1180) en el palacio de las Blanquernas, referidos por Benjamín de Tudela. ${ }^{24}$ En la novela estas escenas se sustituyen por las epopeyas inspiradas en "La faula" de Torroella, que rememoran la leyenda artúrica y los poemas de caballería franceses para enlazar el destino legendario del héroe con la mítica tríada de la Mesa Redonda. ${ }^{25}$ La escena parafrasea desde los muros episodios

22 J. BECKWITH, op. cit., 1997, pp. 184-188. En ella fue recibido Liutprando de Cremona en el año 949 por Constatino VII Porfirogeneta (913 - 959), en cuyo testimonio certifica que la maravilla evocada no es fruto de la fantasía. En la relación, Liutprando de Cremona destaca ante todo los prodigios, pero su apurada descripción no se centra en la arquitectura o el ornato palatino, sino en elementos maravillosos: "Ante el trono del Emperador había un árbol de bronce recubierto de oro, con las ramas repletas de aves de bronce dorado de diversas especies, que emitían diversos cantos según su especie. El trono imperial estaba construido con tal ingenio que en un momento dado aparecía bajo el nivel del suelo o se elevaba en lo alto. Era muy grande y estaba guarnecido por leones de bronce o de madera cubierta de oro, que batían el suelo con sus colas y rugían con la boca abierta al tiempo que movían la lengua". Sus descripciones se encuentran confirmadas por los testimonios de los embajadores de la dinastía china T'ang, que destacaban el decorativismo fulgurante del vidrio y el cristal, del oro, las gemas, el marfil y las piedras preciosas. Los prodigios referidos por embajadores y viajeros ponen de manifiesto el extraordinario interés suscitado por el desarrollo técnico bizantino, favorecido por los estudios técnicos emprendidos por intelectuales árabes y bizantinos que hicieron posible adquirir altas cotas tecnológicas. Estas maravillas sucumbieron víctimas de la crisis iconoclasta y de la destrucción que francos y venecianos infringieron en 1204. Para paliar las necesidades de liquidez del Imperio, Miguel III hizo fundir los autómatas de oro, así como los leones, lo grifos y el árbol que no serían reemplazados hasta el siglo X.

${ }_{23}$ R. KRAUTHEIMER, op. cit., 2000, pp. 406. El Kainourgion era una habitación de planta basilical rematada por un ábside, en cuya nave central se alzaban dieciséis columnas en las que se combinaba el mármol de Tesalia y el ónice, ocho de mármol verde, seis de ónice negro decoradas con pámpanos y dos con acanaladuras en espiral.

24 B. DE TUDELA, op. cit., pp. 64 -66. Véase asimismo la referencia de su viaje en J. BECKWITH, op. cit., 1997, p. 270. El viajero español realiza su descripción impresionado por la belleza de los paneles y la habilidad con la que habían sido dispuestos.

25 G. DE TORROELlA, La Faula, P. BOHIGAS y J. VIDAL (eds.), Tarragona, 1984, versos 543 600. A través de estos mosaicos, Martorell recuperaba con ingenio el emblema del Siti perillós al recrear la investidura del rey Arturo, un símbolo clave para la identificación del monarca que, junto a les garbes de mill bordadas en el manto de Tirant, se convierte en un motivo áulico que comporta implícito un significado cortés. El autor resucita la enseña de Alfonso el Magnánimo y vincula la aventura bizantina del Tirant con el emblema infundido por la leyenda artúrica. La imagen del Siti perillós era reiterada de forma casi obsesiva en su atuendo, en los velas de sus embarcaciones, en sus paveses y banderas, en los uniformes de su ejército. Se extendía incluso a objetos de uso cotidiano, reproducida en manuscritos y plasmada con insistencia en la cerámica 
heroicos en los que el rey Arturo y Gauvain contemplan las gestas de la Antigüedad del mismo modo que en la ficción los personajes son testimonios de los ciclos historiados en tapices y pinturas murales de herencia carolingia. ${ }^{26}$ Esta tradición ornamental se encuentra documentada en la cámara morisca de la Alfajería de Zaragoza por un documento de 1352 que refiere las escenas de la "historia de Jaufré" pintadas en sus muros, que confirman esa íntima fusión que se produjo entre fórmulas artísticas arábigas y cristianas. ${ }^{27} \mathrm{La}$ techumbre es una "soberana cubierta toda de oro y azul" que evoca artesonados como el del Dekanneacubita o salón de los Diecinueve Divanes, la sala de ceremonias remodelada por Constantino Porfirogeneta según el tipo habitual de la sala de banquetes tardorromana, en la que cada uno de los divanes estaba asociado a un nicho, con la mesa imperial en el ábside central. ${ }^{28}$ Estas hornacinas recuerdan a los "festejadors" de los ventanales de los palacios góticos valencianos, en ellos se sientan los protagonistas para refugiarse del alboroto en los festejos. La cubierta recrea la Bóveda Celeste en consonancia con esa afinidad entre aspectos cívicos y religiosos tan propia de estos triclinios que aunaban las funciones de audiencia y servían a su vez como capillas palatinas. Su decoración sugiere artesonados como el de la "Sala Dorada" de la antigua Casa de la Ciudad de Valencia, el del Palacio de la Alfajería de Zaragoza o el del castillo de Santa Coloma de Queralt. ${ }^{29}$ En torno a la cubierta describe "imágenes doradas de los reyes cristianos" y traslada a la cornisa de la sala los retratos de la familia imperial que en realidad bordeaban el friso floral del Koiton, el dormitorio construido por Basilio I frente al Kainourgion ${ }^{30}$.

palatina, afán imbuido de la intencionalidad propagandística de identificar al rey con la caballería ideal de la acreditada materia de Bretaña. En la obra, ambas insignias, junto a la imagen del libro abierto exaltada en la narración de las aventuras de Tirant enlazan con la poesía dirigida al Magnánimo sobre la conquista de Nápoles y su trasunto amoroso con Lucrezia d'Alagno. Si valoramos la globalidad del texto, es justo ésta la única ocasión en que trasluce plenamente el tema, otros motivos o invenciones relacionadas con el Siti Perillós se esparcen en la novela. El más significativo es la silla o trono prohibido, eufemismo tomado para celar el permiso de la Princesa de llegar a tocar con el pie un poco más, lla on la mia amor desija atènyer felicitat completa — cap. 189. Sobre la emblemática del monarca, se recomienda consultar J.V. GARCÍA MARSILLA, "El poder visible. Demanda y funciones del arte en la corte de Alfonso el Magnánimo", Ars Longa, 7-8 (19961997), pp. 39-40; A. HAUF, op. cit., 2005, pp. 488- 489; y R. BELTRÁN, Invenciones poéticas en "Tirant lo Blanc" y escritura emblemática en la cerámica de Alfonso el Magnánimo, Valencia, 2006, pp. 10-12.

26 A. SERRA DESFILIS, "Ab recont de grans gestes. Sobre les imatges de la història i de la llegenda en la pintura gòtica de la Corona d'Aragó", Afers, 41 (2002), pp. 16-20. El gusto por este género de representaciones en el siglo XIII se halla ampliamente reflejado en castillos como el de Claredon, con la leyenda de Ricardo I Corazón de León en la Painted Chamber de Westminster, también en Hessenhof en Alemania, en Lichtenberg, en el Castel Roncolo en Novara en Italia. En los últimos siglos de la Edad Media se constata una mayor preocupación por definir aspectos iconográficos que concreten identificación y contexto en castillos como el de Conflans en Artois, invaden asimismo ámbitos en principio ajenos a la órbita británica como el Palacio del Laterano en Roma o el Palazzo Pubblico de Siena.

27 J. RUBIÓ I BALAGUER, Vida española en la época gótica, Barcelona, 1985, p. 96.

28 R. KRAUTHEIMER, op. cit., 2000, pp. 90. En este tipo de salas el emperador compartía su cena en la coenatio Jovis.

29 J. RUBIÓ I BALAGUER, op. cit., 1985, p. 101.

30 J. BECKWITH, op. cit., 1997, pp. 94-95. La techumbre descansa sobre canes figurativos con las enseñas, armas y epígrafes identificativos de cada monarca, inscritas en caracteres latinos y letras mayúsculas. Martorell es pulcro en el uso de la nomenclatura, bien informado sobre la tradición icónica bizantina, transcribe las inscripciones que identificaban al retratado y confirmaban su veracidad, otorgada por la autoridad de la inscripción. 
El esquema evoca encargos como el de Pedro el Ceremonioso al escultor Aloi de Montbray en 1342 para el "Palacio Real Mayor" de Barcelona ${ }^{31}$. Martorell reelabora el material descrito por las crónicas para crear un programa iconográfico adaptado a los propósitos de la novela y presentar ante Tirant temas y personajes modelados por un sentido instructivo que confirman la ideología monárquica subyacente. ${ }^{32}$

Una vez granjeada su confianza, Carmesina y la emperatriz muestran a sus invitados la torre del tesoro, una cámara fortificada de mármol blanco cubierta por una techumbre dorada cuyo resplandor se alía con la luminiscencia de los interiores recubiertos de mármoles y piedras preciosas que caracterizaba la decoración de salas como el Crisotriclinio ${ }^{(\mathrm{l})}$ construido por Justino II (565-578), o la Triconque ${ }^{(\mathrm{k})}$ edificada por iniciativa de Teófilo (829-842) siguiendo el modelo del Triclinio Áureo. Estas salas ceremoniales eran en definitiva basilicae, suntuosas estancias de planta central circular con funcionalidad múltiple que se abrían a estancias contiguas entorno al patio interno. En este sentido, los personajes concurren una y otra vez en la "gran sala del Palacio" que se entiende como el centro de reunión de los estratos cortesanos con una vocación burocrática. Por sus características y ubicación se percibe un espacio asociable al Gran Consistorio ${ }^{(\mathrm{h})}$, la sala del trono y de audiencia de la Divina Majestad Imperial empleada en las recepciones oficiales ${ }^{33}$. Las descripciones conservadas remiten de hecho a arquitecturas fabulosas de plantas trilobuladas, entrelazadas mediante pórticos abovedados en una sucesión de polígonos a través de la combinación de ábsides, rotondas, hexágonos y octágonos recubiertos de mosaicos, jaspes, ónices y mármoles que hacen verosímil la recreación de la novela. Recrea así estancias cupuliformes que trasladan al lector la impresión difusa de un palacio que se desplegaba en pabellones independientes articulados a través de patios internos, corredores y terrazas. Esta composición se aleja del sistema de palacio compacto, y responde a la perfección al complejo ceremonial de la corte en el que la familia imperial transitaba en procesión, atravesando pequeños jardines, terrazas y pórticos de columnas.

\section{Los apartamentos personales de la familia imperial}

El recorrido por el palacio está estratégicamente orquestado por el escritor, al atravesar el portal de entrada el cortejo accede directamente al Palacio de Dafne ${ }^{(\mathrm{i})}$, el conjunto de edificaciones privadas que conformaban las residencias imperiales en

31 J. RUBIÓ I BALAGUER, op. cit.,1985, p. 97. En la relación cita también la galería de los reyes de Aragón que la Diputació de Catalunya encomendó a Ariosto en el siglo XVI. Igualmente en París, la antigua sala del palacio estaba decorada con estatuas de los monarcas franceses. En la Península, el friso del salón de Embajadores del Alcázar de Sevilla contenía efigies sedentes de los monarcas hispánicos, la sala de reyes de Segovia ofrece ejemplos similares.

32 A. SERRA DESFILIS, op. cit., 2002, pp. 16-22. Se trataba de una compleja iconografía destinada a exaltar la autoridad soberana e incitar al protagonista a emular su conducta y reconocer su filiación.

33 R. KRAUTHEIMER, op. cit., 2000, pp. 90-91. Su uso como capilla no está documentado hasta el siglo pero la interpenetración de la esfera civil y religiosa se remonta a época tardorromana por lo que resulta lógica en el ámbito bizantino la transferencia de ambas funciones en el complejo palatino, donde la estancia seguiría el mismo uso que el triclinio de la Domus Aurea de Nerón o el Octógono Dorado de Constantino en Antioquía. 
sentido estricto. Esta hipótesis casaría perfectamente con los acontecimientos planteados en los episodios sobre la corte bizantina ya que en este sector se ubicaba la Kathisma $^{(\mathrm{j})}$ o logia imperial desde la cual los emperadores asistían a les ceremonias y carreras del Hipódromo ${ }^{(\mathrm{p})}$. La compartimentación de las salas privadas da pié a tramas picarescas como contrapunto de la seriedad de los actos de caballería, se convierten en escenarios improvisados para las travesuras amorosas, y es en la descripción de estos ámbitos íntimos donde el autor se permite mayores licencias, donde la sugestión invalida cualquier confrontación con la realidad. En este entorno un intento de concretar la trayectoria de los protagonistas sobre el plano resultaría inútil, innecesario para captar la esencia ambiental.

En el Gran Palacio las habitaciones privadas se concentraban a un lado del Consistorio en el lado opuesto al Triclinio, rodeadas por los jardines imperiales. Estaban concebidas como bloques rectangulares independientes, cada uno dividido en una sala principal rodeada por filas de estancias abovedadas comunicadas entre sí, dotadas de terraza y con acceso directo al jardín que las envolvía. En la novela, la decoración y el mobiliario revelan la distribución interna de estos apartamentos, que constaban de una antecámara de recepción en la que transcurría la vida cotidiana, dormitorios para doncellas y pajes, una habitación principal y diversos gabinetes destinados al aseo y la oración, que solía comunicar con una terraza posterior para acceder a un huerto situado a espaldas del palacio. Estos huertos eran ámbitos para el esparcimiento, para paseos y juegos, con frecuencia al cuidado de labradores o esclavos, como el negro Lauseta en nuestra novela. Edificios para la vivienda de los hortelanos y guardar las herramientas de cultivo completaban su paraje. En realidad, la compartimentación interna de los aposentos palaciegos no difería en lo esencial, ajustándose en dimensiones a una base estructural común ${ }^{34}$. Martorell aprovechó este trazado propio de los palacios y las villas tardorromanas y paleocristinas para evocar unos habitáculos cuya decoración y mobiliario recogían la influencia de los interiores de los palacios italianos de los siglos XIV y XV ${ }^{35}$. La higiene personal se disponía en los reservados que contaban con bañeras de cobre para el baño, cofres esculpidos para guardar toallas y ropa de cama, espejos y tocadores para peinarse. El habitáculo se completaba con un icono de la Virgen, justamente incorporada para situar la escena en el contexto de la órbita ortodoxa, dada la especial veneración en Constantinopla de la Theotokos Hodegetria ${ }^{36}$. Su ubicación en el oratorio privado de la doncella

34 J. RUBIÓ I BALAGUER, op. cit.,1985, pp. 91-92. La distribución de las dependencias se deduce en la novela a partir de citas puntuales y dispersas, en función del argumento. Rubió i Balaguer trae a colación la reforma encargada por Alfonso el Magnánimo para el Real de Valencia por medio de unas cartas sin fecha donde especifica el número de estancias, las dimensiones apropiadas y el uso al que se destinarían.

35 P. THORNTON, The Italian Renaissance Interior. 1400-1600, New York, pp. 285-300. Estudia la distribución interna de los aposentos de los palacios italianos, que se había extendido a una amplia órbita de influencia y revelan aspectos parejos a los reflejados por la novela.

36 J. BECKWITH, op. cit., 1997, pp. 97-98. La imagen aquiropoeta de la Theotokos Hodegetria atribuida a San Lucas era objeto de especial veneración en Constantinopla, pues según la leyenda había sido enviada a Constantinopla desde Jerusalén por la emperatriz Eudosia a su cuñada Pulqueria en el año 438, quien mandó construir para ella una iglesia en el interior del Sagrado Palacio Imperial. Esta tradición se remonta al historiador de principios del siglo VI Teodoro Anagnostes, cuya obra subsiste por las copias del siglo XIV. Con todo, son abundantes las referencias al icono en el siglo X en la obra de Teófanes Continuato y en el siglo XII 
respondería al principio según el cual la mujer necesitaba objetos de devoción, no de instrucción. Completando la escena, incluso el olfato se satisface con el perfume de la aliaga esparcida por el suelo. Tras recopilar las referencias, al comparar la estructura propuesta con las habitaciones de la reina María de Castilla en el Real de Valencia, se ratifica la veracidad de la relación aportada. El inventario del 4 de septiembre de 1458 proporciona un referente de contraste para el contexto ofrecido en la novela, haciendo plausible la comprensión del palacio bizantino. ${ }^{37}$ Una vez visitado el entorno, resulta más plausible reconocer el plano del Sagrado Palacio propuesto por Vogt, precedido por la Chalke, con el patio de entrada situado justo detrás, bordeado por los pabellones de la guardia imperial. La distribución abierta y libre, se infiere trazada por laberinto que explica la desenvoltura de la vida cortesana plasmada en el relato.

\section{Conclusiones}

Valorar la noticia de un recinto monumental tan emblemático en un texto literario implica descubrir las fuentes, ponderar su repercusión y la manipulación subsiguiente efectuada por el autor en el ejercicio libre de su creatividad. No hay ninguna constancia documental de una posible estancia de Martorell en Constantinopla y con todo demuestra tener unas nociones muy claras de aquello que le interesaba recuperar, al trasladar al fondo escénico la responsabilidad de hacer asumible la ficción mediante una fascinante combinación de maravilla y realidad. El Gran Palacio Imperial, como los restantes paisajes del relato, participa de este doble compromiso con la verosimilitud y la invención en cuyo análisis no se muestra jamás azaroso ni precipitado. En el escrutinio del ambiente palatino aprovecha la conjunción de circunstancias esenciales y no esenciales para dotar de versatilidad al relato, en un equilibrio en que no es posible distinguir el elemento natural del postizo, coordinados, como afirmara Vargas Llosa, en una perfecta ósmosis de componentes de filiación diversa ${ }^{38}$. Precisamente en este episodio Martorell exprime los recursos, para recrear un ambiente palatino veraz, y allá donde la certeza no llega a proporcionar datos fiables, desdibuja la escena en una imagen difusa en la que cabe suspender la lógica analítica y dejar paso a la fruición. La novela se erige así en una valiosa fuente de información histórica, que desvela el interés de la Europa contemporánea por conocer la realidad bizantina, las especulaciones que circulaban en torno a su historia y circunstancia.

a través de Nicolás Mesarita y Antonio de Novgorod. Los devotos en la ciudad sostenían que el icono había sobrevivido a la destrucción iconoclasta para el que Miguel III Paeólogo erigió una iglesia en el barrio de las Magnanas, cerca de un manantial milagroso cuyas aguas curaban la ceguera, de ahí el nombre de Hodegetria, la que señala el camino.

37 J. TOLEDO GIRAU, Inventarios del Palacio Real de Valencia a la muerte de doña María, esposa de Alfonso el Magnánimo, Valencia, 1961, pp. 45-61. Sobre el Palacio del Real y las obras llevadas a cabo durante el reinado de Alfonso el Magnánimo, M. GÓMEZ-FERRER, "La reforma del Real Vell de Valencia en época de Alfonso el mangnánimo: Recuerdo del Palacio desde Sicilia", Lexicon. Storie e Architettura in Sicilia, 8 (2009), pp. 7-22. Sobre la distribución funcional de las dependencias que ocupaba la reina María, en torno al llamado patio de la Reina, véase M. GÓMEZ-FERRER, El Real de Valencia (1238-1810): historia arquitectónica de un palacio desaparecido, Valencia, 2012, pp. 123-127.

38 M. VARGAS LLOSA, op. cit., 1991, pp. 34-35. 